\title{
Paste fill stiffness investigation
}

\author{
James De Villiers Wickens \\ Paterson \& Cooke Consulting Engineers (Pty) Ltd, South Africa
}

Stephen Wilson

Paterson \& Cooke UK Ltd, England

SUMMARY: When conducting a backfill test campaign based on the selected mining method, there are various types of tests that are usually conducted to understand the in-situ behaviour of the material when placed underground. The unconfined compressive strength (UCS) and modulus of elasticity are the two most commonly measured parameters when dealing with a cemented paste fill material. However, when dealing with complex ore bodies or extraction techniques, additional testing, including triaxial and consolidation can be required to better understand the material's behaviour when exposed to a sustained ground load. This is of particular interest in yielding or closing ground conditions. The modulus of elasticity results, measured by conducting a UCS test, provides information on the strength of the material and the ability to resist deformation under load when the fill is exposed vertically and horizontally. However, when dealing with long term stability and support, it is important to understand the stiffness of the material and how it will resist deformation when exposed to different loading conditions when confined.

This paper will present selected triaxial and consolidation test data for a range of material blends, considerations that defined the testing program, and the nature of the tests performed. Conclusions will be presented as to the significance of the selected testing methodologies on the results obtained and their applications for industry.

Keywords: unconfined compressive strength, triaxial, backfill, modulus of elasticity and modulus of stiffness

\section{INTRODUCTION}

Before commencing with a backfill test campaign, it is important to understand how the backfill will be used and how it should perform. Key to the selection of a backfill type, other than the well established commercial drivers, is an understanding of how the material is required, or expected to behave within the proposed mining method or application. It is also important to develop a material testing program to support the engineering and project development process. Such a program must give consideration to the material available for backfill, the mining methodology and the anticipated ground conditions, including the development of vertical and/or horizontal ground stresses that may influence the backfill, and against which the backfill performance specifications must be developed.

The data presented within this paper are derived from a large, multi-phased test work program undertaken by Paterson \& Cooke in its Cape Town laboratory. The project requirements for backfill included:

- Bulk mining extraction methods,

- High ore body extraction ratios,

DOI: $10.1201 / 9781003205906-2$ 
Table 1. Test matrix.

\begin{tabular}{lllll}
\hline Number & Constituted mixture & Concentration & Water/Cement ratio & Cement addition \\
\hline 1.1 & 75SN/25TA & $75 \% \mathrm{~m}$ & $4.76 / 1$ & $7 \%$ \\
2.1 & 60SN/40TA & $71 \% \mathrm{~m}$ & $5.83 / 1$ & $7 \%$ \\
3.1 & 60SN/20TA/20TB & $76 \% \mathrm{~m}$ & $4.51 / 1$ & $7 \%$ \\
3.2 & 50SN/30TA/20TB & $74 \% \mathrm{~m}$ & $5.02 / 1$ & $7 \%$ \\
4.1 & 50SN/40TA/10TB & $72 \% \mathrm{~m}$ & $5.56 / 1$ & $7 \%$ \\
4.2 & 40SN/40TA/20TB & $71 \% \mathrm{~m}$ & $5.83 / 1$ & $7 \%$ \\
5.1 & 60SN/20TAC/20TB & $81 \% \mathrm{~m}$ & $3.35 / 1$ & $7 \%$ \\
5.2 & 60SN/5TA/15TAC/20TB & $80 \% \mathrm{~m}$ & $3.57 / 1$ & $7 \%$ \\
5.3 & 60SN/10TA/10TAC/20TB & $79 \% \mathrm{~m}$ & $3.81 / 1$ & \\
\hline
\end{tabular}

- Modest mining horizons extending up to $800 \mathrm{~m}$ below surface, and

- A rockmass with a tendency for convergence or closure.

As a consequence of the above project conditions, it was necessary to investigate a backfill not only with a target strength, but also a target stiffness, and indeed the stiffness target predicates the backfill strength specification, it being the more onerous condition. The anticipated sustained vertical and horizontal loading forecasts for the project indicated a target stiffness in the order of $100 \mathrm{MPa}$.

The project was able to consider a number of component backfill products, including two tailings types and an imported sand product. Further more, the option to cyclone one of the tailings products was also available for consideration. In order for the test work program to adequately investigate and develop a backfill product to meet these criteria, the following tests were considered for this test program:

1. Material properties tests,

2. Rheology tests,

3. Unconfined compressive strength and modulus of elasticity tests,

4. One-dimensional consolidation testing and

5. Unconsolidated-Undrained triaxial tests.

\subsection{Test matrix}

Table 1 presents the test matrix and mix reference. The following abbreviations are used:

- SN: Sand

- TA: Tailings A

- TAC: Tailings A Cycloned

- TB: Tailings B

Development of this test matrix followed a number of previous test campaigns which enabled iteration and refinement of the mix designs towards attaining the target specification.

\section{MATERIAL PROPERTIES TESTS}

\subsection{Solids density}

The solids density of the samples was determined using a helium pycnometer, which measures the skeletal solids density. Table 2 presents the measured solids densities.

Table 2. Solids densities.

\begin{tabular}{ll}
\hline Sample reference & Solids density $\left(\mathrm{kg} / \mathrm{m}^{3}\right)$ \\
\hline Tailings A & 2654 \\
Tailings A cycloned & 2641 \\
Sand & 2753 \\
Tailings B & 2495 \\
Cement & 3015 \\
\hline
\end{tabular}




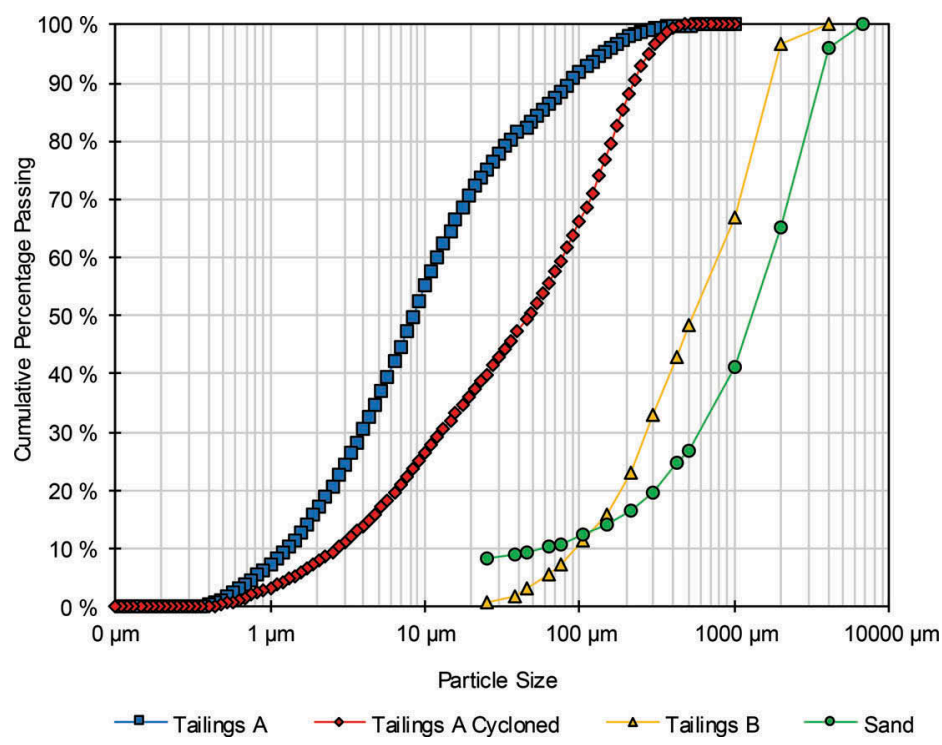

Figure 1. Particle size distributions.

\subsection{Particle size distributions}

The particle size distributions (PSD) of the as-received materials were determined by wet sieving and laser diffraction. Figure 1 presents the measured PSD data.

\subsection{Cement quality}

A CEM III/B $32.5 \mathrm{~N}$ cement was supplied for the test work. Before commencing with the test work, cement mortar tests, according to EN 196-1:2005 Edition 2, were carried out to determine the quality of the cement. The 28-day results showed a compression strength of 34.8 $\mathrm{MPa}$ which exceeds the minimum required compressive strength of $32.5 \mathrm{MPa}$ indicating that the cement complied with the standard requirements.

\section{RHEOLOGY TESTS}

An Anton Paar Rheolab QC rotational viscometer was used for the test work. The slurries were tested and analysed according to the infinite bob and cup method described by Chhabra \& Richardson (1999). The data were analysed by applying the Bingham plastic model which is a two-parameter model describing the slurry rheology.

Figure 2 shows the rheogram for the various mixes. The data show that the yield stress varies from $\sim 120$ to $\sim 260 \mathrm{~Pa}$ for the various constituted mixes.

\section{UNCONFINED COMPRESSIVE STRENGTH AND MODULUS OF ELASTICITY TESTS}

\subsection{Cement addition and water/cement ratio}

The percentage cement addition and water/cement ratio are calculated using the following formulas:

$$
\text { Percentage cement }=\frac{\text { mass of cement }}{\text { mass of solids }+ \text { mass of cement }}
$$




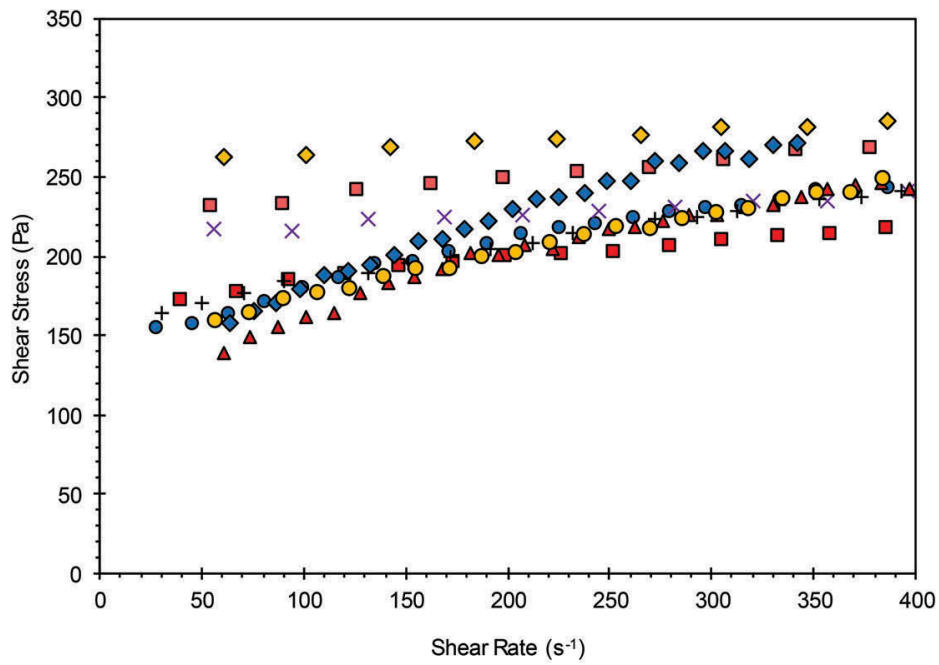

- Mix $1.1 \diamond \operatorname{Mix} 2.1 \bullet \operatorname{Mix} 3.1 \times \operatorname{Mix} 3.2+\operatorname{Mix} 4.1$ ㅁix 4.2 $\bullet \operatorname{Mix} 5.1 \Delta \operatorname{Mix} 5.2 \circ \operatorname{Mix} 5.3$

Figure 2. Rheogram for Mixes 1.1 to 5.3 .

$$
\text { Water : Cement Ratio }=\frac{\text { mass of water }}{\text { mass of cement }}
$$

\subsection{Test results}

Table 3 shows a summary of the w/c ratio at which the mixes were constituted, the cylinder (fill) density, the UCS and the modulus of elasticity. Figure 3 shows the UCS and modulus of elasticity test results versus the constituted mixtures. The data show that the mixes with a w/c ratio lower than 5/1, yield the highest results in terms of UCS and modulus of elasticity. Also evident from the data is that the proportionality between UCS and modulus of elasticity is not uniform, confirming the assertion that the different material blends, and importantly, the associated changes in overall particle size distribution of the final mixture, influence the geomechanical response of the backfill.

Table 3. UCS and modulus of elasticity test results.

\begin{tabular}{lllll}
\hline $\begin{array}{l}\text { Mix } \\
\text { Number }\end{array}$ & $\begin{array}{l}\text { Water/Cement } \\
\text { Ratio }\end{array}$ & $\begin{array}{l}\text { Cylinder Density } \\
\left(\mathrm{kg} / \mathrm{m}^{3}\right)\end{array}$ & $\begin{array}{l}\text { 28 Day UCS } \\
(\mathrm{kPa})\end{array}$ & $\begin{array}{l}\text { 28 Day Modulus of } \\
\text { Elasticity } \\
(\mathrm{MPa})\end{array}$ \\
\hline 1.1 & $4.76 / 1$ & 1927 & 2212 & 341 \\
2.1 & $5.83 / 1$ & 1845 & 2067 & 333 \\
3.1 & $4.51 / 1$ & 1923 & 2369 & 140 \\
3.2 & $5.02 / 1$ & 1859 & 2686 & 327 \\
4.1 & $5.56 / 1$ & 1712 & 1085 & 84 \\
4.2 & $5.83 / 1$ & 1786 & 1696 & 119 \\
5.1 & $3.35 / 1$ & 2024 & 3025 & 366 \\
5.2 & $3.57 / 1$ & 2009 & 2928 & 336 \\
5.3 & $3.81 / 1$ & 1955 & 2851 & 322 \\
\hline
\end{tabular}

\footnotetext{
${ }^{1}$ Secant modules based on 25 and $75 \%$ of UCS.
} 


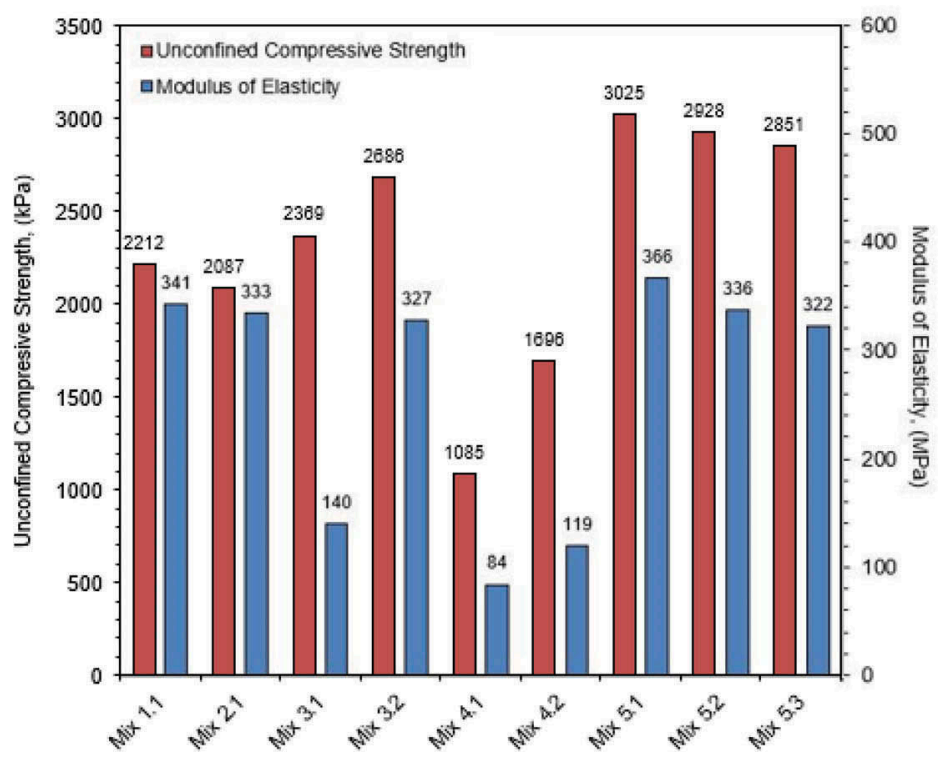

Figure 3. Unconfined compressive strength and modulus of elasticity vs mix number.

\section{ONE-DIMENSIONAL CONSOLIDATION TESTS}

One-dimensional consolidation tests are conducted at axial loading pressures ranging from 10 to $25000 \mathrm{kPa}$ to simulated ground load conditions which is based on the mining plan. For this particular test work program, the maximum axial load considered was $6400 \mathrm{kPa}$. Figure 4 and Figure 5 show the axial stress versus axial strain and void ratio versus axial stress repectively. The axial stress versus axial strain data indicates that the voids are compressed up to an axial stress of $800 \mathrm{kPa}$. This is evident as an exponential increase in the stress versus strain is seen, where a more linear relationship is seen at axial stress values above $800 \mathrm{kPa}$.

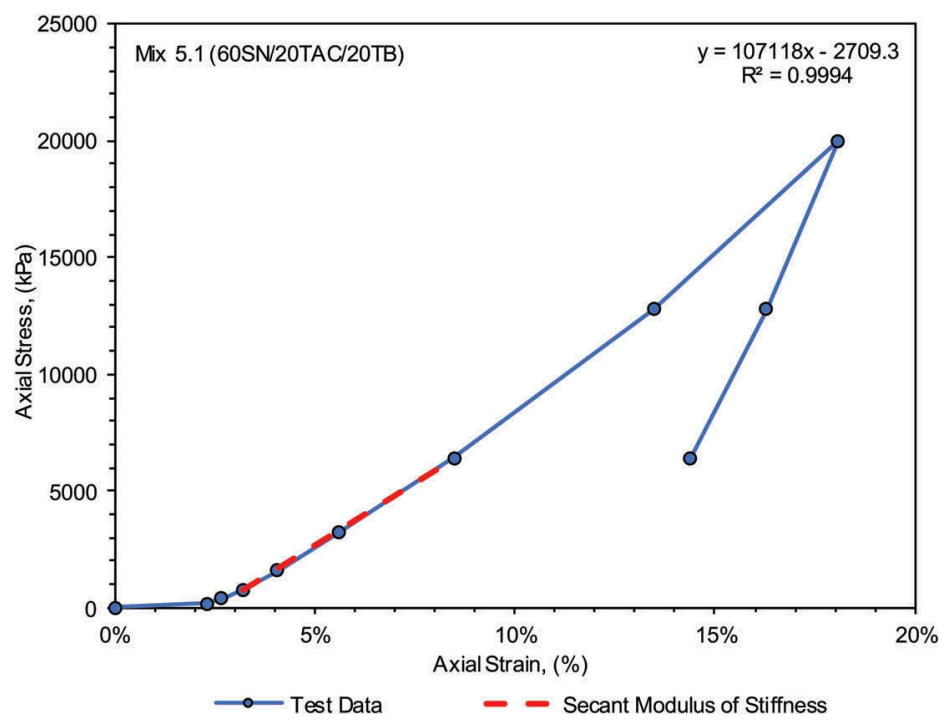

Figure 4. Axial Stress vs Axial Strain for Mix 5.1. 


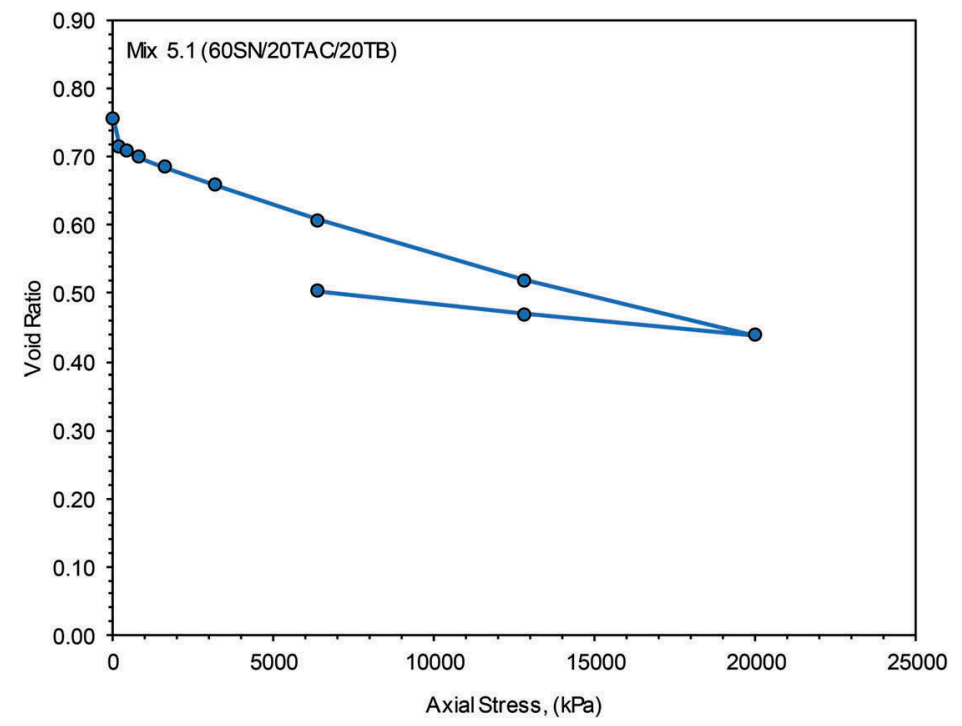

Figure 5. Void Ratio vs Axial Stress for Mix 5.1.

Table 4. Secant modules of stiffness results.

\begin{tabular}{llll}
\hline Mix Reference & Water/Cement Ratio & Axial Stress Range $(\mathrm{kPa})$ & Secant Modulus of Stiffness (MPa) \\
\hline 1.1 & $4.76 / 1$ & $800-6400$ & 59 \\
2.1 & $5.83 / 1$ & & 54 \\
3.1 & $4.51 / 1$ & 69 \\
3.2 & $5.02 / 1$ & 67 \\
4.1 & $5.56 / 1$ & 36 \\
4.2 & $5.83 / 1$ & 46 \\
5.1 & $3.35 / 1$ & 107 \\
5.2 & $3.57 / 1$ & 106 \\
5.3 & $3.81 / 1$ & 92 \\
\hline
\end{tabular}

Table 4 and Figure 6 show the average modulus of stiffness results for each mixture, with Figure 7 showing the change in void ratio at different axial loads for each mixture. As seen from the UCS and modulus of elasticity test results, the lower the water/cement ratio and subsequent denser fill, the higher the starting void ratio which results in a higher modulus of stiffness.

\section{UNCONSOLIDATED-UNDRAINED TRIAXIAL TESTS}

Table 5 and Figure 8 present the unconsolidated-undrained triaxial results. Mix series 3 and 5 yield the highest results in terms of effective cohesion, thus aligning with the UCS results presented earlier. The effective angle of friction varied from $18^{\circ}$ at the lowest to $39^{\circ}$ at the highest.

\section{CONCLUSIONS}

This paper presents the results of a series of tests conducted using various blends of materials in order to determine the mixture with the highest modulus of stiffness. The main conclusions are as follows: 


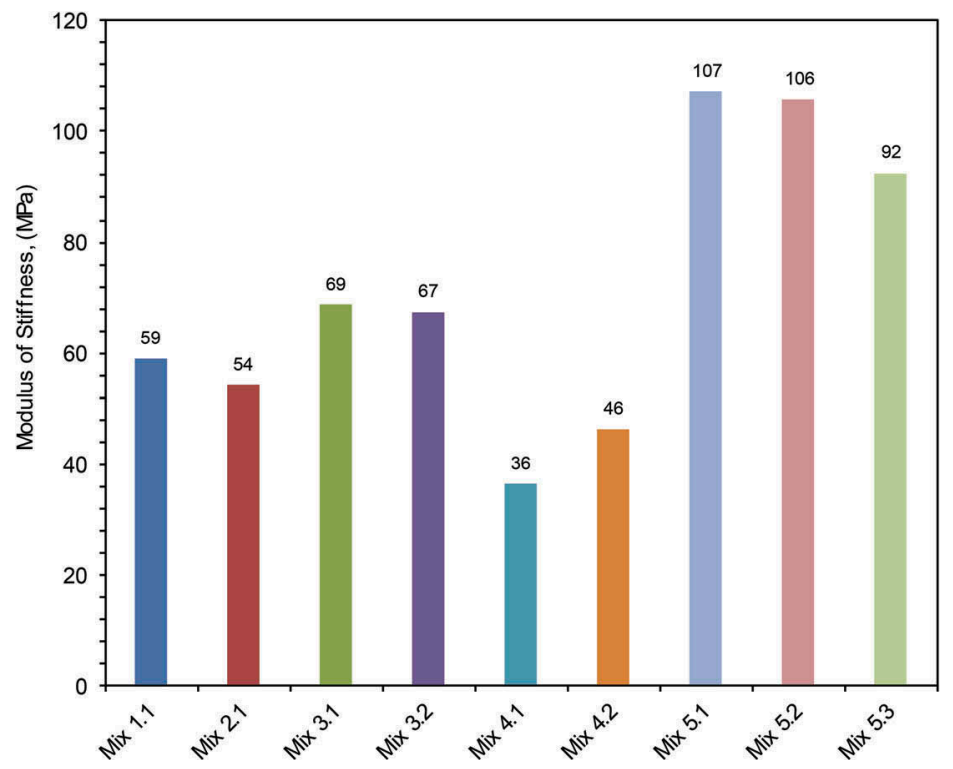

Figure 6. Modulus of stiffness vs mix number.

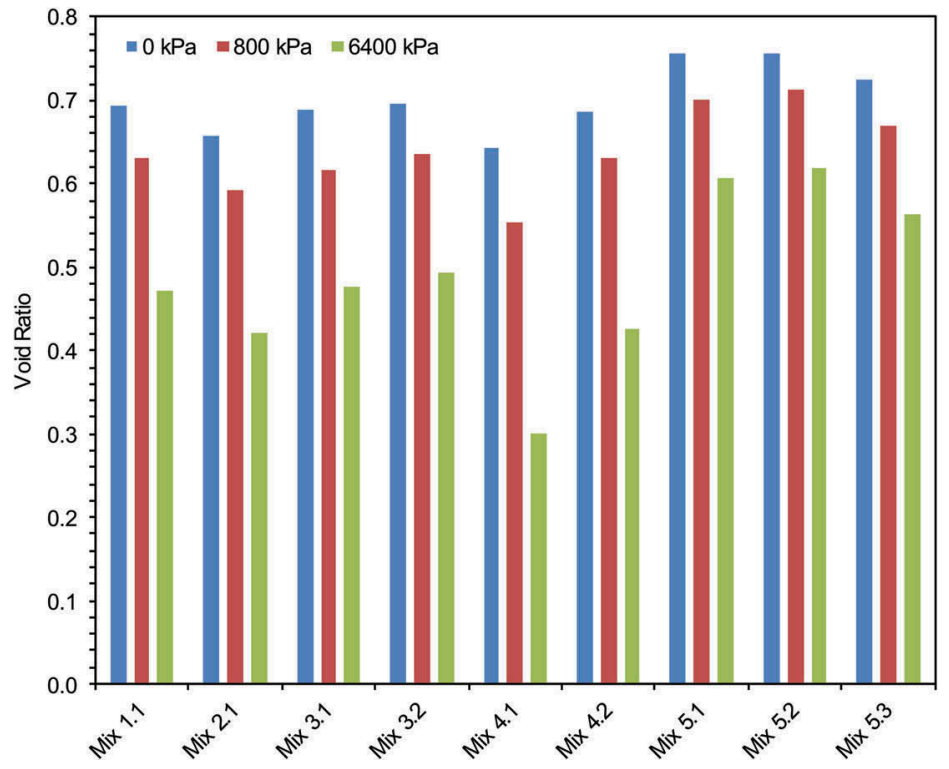

Figure 7. Change in void ratio at different axial loads vs mix number.

1. Before commencing with any test work, it is important to understand what type of mining plan is to be used and what the purpose of the backfill should be, as well as how the host rock will behave under loading conditions. Once this has been established, the test work program should be developed to measure the required parameters in order to ensure that the backfill will meet the requirements. These parameters can vary from the UCS and 
Table 5. Unconsolidated-undrained triaxial test results.

\begin{tabular}{llll}
\hline Mix Reference & Water/Cement Ratio & Effective Cohesion c' & Effective Angle of Friction $\phi$ \\
\hline 1.1 & $4.76 / 1$ & $680 \mathrm{kPa}$ & $26.5^{\circ}$ \\
2.1 & $5.83 / 1$ & $710 \mathrm{kPa}$ & $18.0^{\circ}$ \\
3.1 & $4.51 / 1$ & $850 \mathrm{kPa}$ & $24.5^{\circ}$ \\
3.2 & $5.02 / 1$ & $835 \mathrm{kPa}$ & $23.0^{\circ}$ \\
4.1 & $5.56 / 1$ & $223 \mathrm{kPa}$ & $29.0^{\circ}$ \\
4.2 & $5.83 / 1$ & $487 \mathrm{kPa}$ & $29.0^{\circ}$ \\
5.1 & $3.35 / 1$ & $658 \mathrm{kPa}$ & $37.0^{\circ}$ \\
5.2 & $3.57 / 1$ & $804 \mathrm{kPa}$ & $33.0^{\circ}$ \\
5.3 & $3.81 / 1$ & $820 \mathrm{kPa}$ & $31.0^{\circ}$ \\
\hline
\end{tabular}

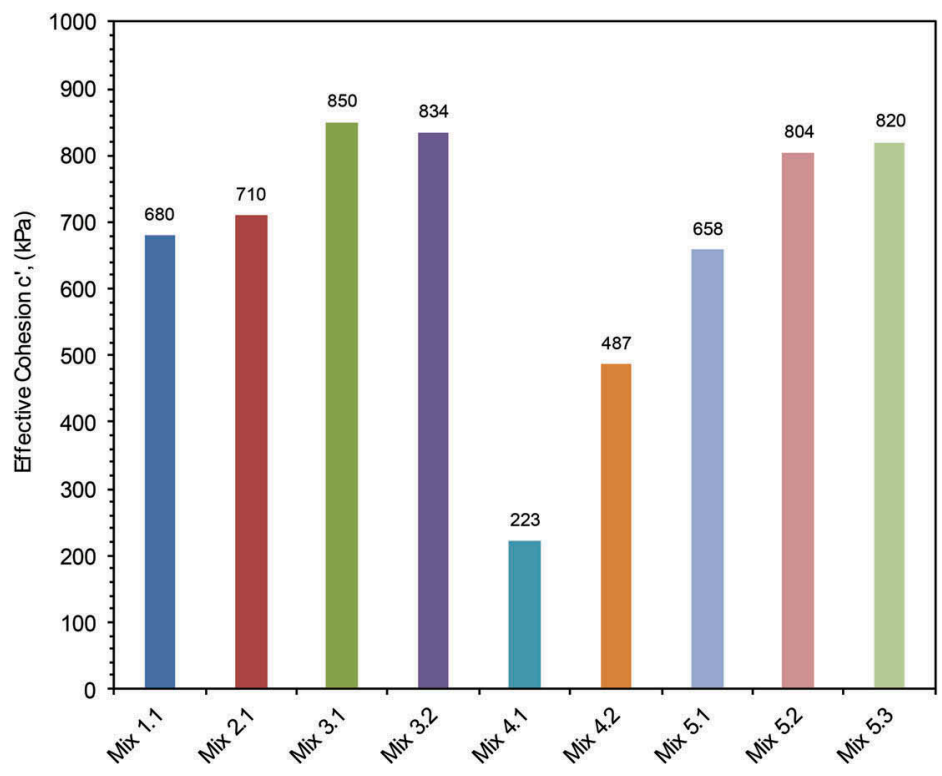

Figure 8. Effective cohesion versus mix number.

modulus of elasticity (understand how the backfill will behave when vertically exposed) to the modulus of stiffness (long term stability and support).

2. The tests data indicated that the mix series five yielded the highest results in terms of UCS, modulus of elasticity and modulus of stiffness. The starting void ratios for these mixes were above 0.7 where all the other mixes were below 0.7 . At an axial load of $6400 \mathrm{kPa}$, the void ratios for these mixes were only compressed to above 0.55 , where all the others were compressed to below 0.50 .

3. The unconsolidated-undrained triaxial test results indicated that very similar effective cohesion results were measured for the majority of the mixes, except for mix series four. Mix series five had the highest effective angle of friction of above $31^{\circ}$ compared to the other mixes where effective angles of friction of $29^{\circ}$ and lower were recorded.

Overall the test work program sought to obtain a mix design that could deliver a stiffness in excess of $100 \mathrm{MPa}$. Through the test work program, the data were able to substantiate that mix series 5 provided the best opportunity to attain this, and it is notable that this mixture contained the lowest fines content and returned the highest in-situ density of all the mixes prepared. 


\section{ACKNOWLEDGEMENT}

The authors would like to acknowledge the contribution of Paterson \& Cooke Cape Town laboratory staff for their contribution in assisting with the test work.

\section{REFERENCES}

ASTM International 2000b, ASTM D2166 Standard Test Method for Unconfined Compressive Strength of Cohesive Soil, ASTM International, West Conshohocken.

ASTM International 2002, ASTM D4832 Standard Test Method for Preparation and Testing of Controlled Low Strength Material (CLSM) Test Cylinders, ASTM International, West Conshohocken.

European Standard 2005, EN 196-1 Method of Testing Cement - Part 1: Determining Strength, Brussels.

British Standard 1975, BS 1377 Methods of Test for Soils for Civil Engineering Purposes - Part 5 and 8, Chiswick London. 